\title{
Nance-Horan syndrome
}

INSERM

\section{Source}

INSERM. (1999). Orphanet: an online rare disease and orphan drug data base. NanceHoran syndrome. ORPHA:627

Nance-Horan syndrome (NHS) is characterized by the association in male patients of cong enital cataracts with microcornea, dental anomalies and facial dysmorphism. 